\section{Visualizing a Critical Mixed-Race Theory}

ABSTRACT: In this paper, questions regarding the cultural understanding of mixed race are explored, which have the ability to complicate the accepted portrayal of race in society as a black/white binary system. Thus, the acknowledgement of something other than this binary system offers new ways of theorizing about race, particularly concerning the sociopolitical implications of mixed-race designation. This paper argues that the visually mixed-race person has a certain direct ability to challenge the binary and its racist logic. Furthermore, this paper goes on to offer a unique interpretation of where power for working against a racially oppressive system lies within critical mixed-race theory.

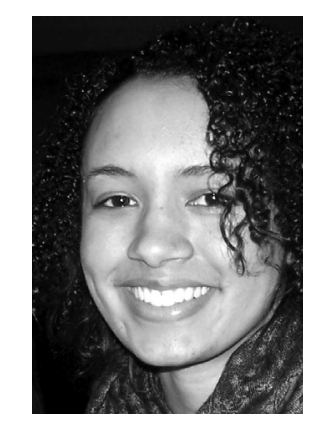

Desiree Valentine is currently a junior at Marquette University majoring in both Philosophy and Communication Studies. Her interests across disciplines are focused in social, cultural, and political issues. She enjoys feminist philosophy and the philosophy of race. Desiree is particularly interested in philosophica inquiry that is grounded in lived experience and enjoys questions of identity, subjectivity, and embodiment in terms of one's gendered and raced socia reality. As a philosophy major, one of Desiree's main goals is to apply philosophical theory to everyday practice; therefore, she takes a keen interest in social activism and community organizing.

๘

as in kindergarten when I had a clear binary system and thus offer new ways of understanding of the racialized world in theorizing race as well as the sociopolitical my school registration papers recognizing myself as either black or white. This simple action can be quite complicated when one is a daughter of a black father and white mother. was finally offered the choice of "mixed" by the time I reached Jr. High. But what is this concept of "mixed" and what does it offer a nation still infused with racism years after the time period known as the "Civil Rights Era" has ended?

Questions of mixed race bring with them complications to the established black/white implications of mixed race designation. As Lewis Gordon states, "In spite of contemporary resistance to 'binary' analyses, a critical discussion of mixed-race categories calls for an understanding of how binary logic functions in discourses on race and racism. Without binaries, no racism will exist."1 Can a breakdown of the current binary logic, which places social and political advantages on white individuals, occur with the inception of a critical mixed race theory? And could this lead to a society $t$ This essay will focus on the views of theorists
Lewis Gordon and Naomi Zack and their conceptions of the racial binary system and mixed race. I will begin by looking at both theorists' views on the racial binary system, posing the question, "How do we understand the spectrum of race?" From there, I will explore the approaches each theorist offers for deconstructing the binary each theorist offers for decontry followed by a companson and critique of both theorizations, with the end goal of offering my own interpretation of where power for working against a racially oppressive system lies within a critical mixed race theory. It is my view that what often gets overlooked in these theorizations is the effect of visual incoherency to the black/ white binary that can be provided by the mixed race individual. The concept of the "visibly mixed race person" will be used in this essay to explore the transformative areas for a society still enmeshed in the ugly history of racism.

Interpretations of the Racial Binary System

Zack's book Race and Mixed Race focuses on American categories of racial inheritance and racial identification. For Zack the racial binary is understood clearly as black/white because is understo car modes of mheritance and identification are set up such that an individual fits in either one or the other. As she describes, the ordinary concept of race rests solely on the "asymmetrical kinship schema" (commonly referred to as the "one drop rule"). In this schema, having at least one black relative any number of generations back is a sufficient condition to be categorized "black." For an individual to be designated white, all of his or her past relatives must have been white. s Zack notes

The schema implies that both whiteness nd blackness are defined in terms of blackness. Thus American racial categories re interdependent, and because there is no cial categories are groundless-they have no mpirical foundation. ${ }^{2}$

Since race has no adequate scientific asis, Zack maintains that "black and white racial designations are themselves racist." furthermore, she argues, the binary American racial system precludes a "mixed race" category. Therefore, for Zack, the binary of race in the United States is understood as distinct pole of black and white, upheld by paradigmatic ideals of "pure" American blacks and "pure" ideals "pune American blacks and "pure" American whites as co he kinship schema.

In contrast, Gordon formulates the ide of the binary as a sliding scale hierarchy in which the division is into white and non-white. Gordon bases this on the lived experience and sociopolitical implications of appearing "more white" or "less black." He describes whitenes

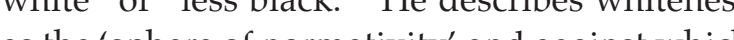
as the 'sphere of norm the norn ind stands at the top of the social value system. Thus follows hierarchical yet still Manichean framework. The divisions within each pole describe mutually exclusive, antagonistic categories of value and offer a more fluid concept of "blackness" or "whiteness" based on the varying degree of skin tone. This measure of degree benefits lighter skin by placing it towards the top of the hierarchy. 
Gordon describes the binary as having two main because of the antiblack racist context. He principles: “(1) be white ... (2) don't be black." ${ }^{5}$ argues that a fundamental change in this racial Here is the major difference between Zack binary logic must occur and a critical mixed-race and Gordon. Based on Zack's binary, a mixed position to this contention cannot accomplish race category is disallowed. Gordon's analysis these goals. Both of these principles (1- be white cocounts for mixed race within binary racial and 2-don't be black) must be rejected in order e rejected in order logic. However, both agree that any binary to eliminate the racist foundation of the racial construction stands to have racist foundations binary and therefore, racism itself. and thus should be deconstructed.

Approaches to Breaking down the Racial Binary

Zack posits that having more people selfidentify as "mixed race" will work as a way to break down her theoretical binary, where any designation other than "black" or "white" violates the established binary. Thus, establishing oneself as "mixed" will work in establishing oneself as "mixed" will work in eradicating racism by causin

the system that sustains it.
Zack argues that creating a racial identity is existentially harmful to the individual because race is a myth perpetuated by the oppressors should be rejected. Rejecting these ordinary concepts of race within the binary (such as concepts of race within the binary (such as
"black" or "white") could lead to the eradication of racism in her view. The moment of confusion and the need for new social constructions after eliminating current concepts of race is see as an opportunity to end racism. The "mixe race" designation stands as the "anti-race" as it refuses to be reduced to established categories and thus creates the opportunity to transform and thus creates the opportu

Incontras

In contrast, Gordon argues against mixed-race identification as a method to eradicate racism A mixed-race racial position is compatible with the rejection of principle (1), but it is no compatible with the rejection of principle (2) That is because there is no way to reject the thesis that there is something wrong with being black beyond the willingness to "be" blacknot in terms of conven blackness, but by paying the social costs of antilacks but by paying the social costs of anti-

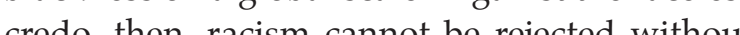
a dialectic in which humanity experiences a blackened world. ${ }^{6}$

Gordon makes the argument that because of the sliding scale hierarchy of binary racial logic and the existence of whiteness as the normative (and thus raceless) standpoint, if the outward designation of mixed race, she runs into difficulties. Naturally, one cannot "equalize" elements that are not perceived as equals in the sociopolitical world withou gaining "unequal" sociopolitical consequences We can see that an equalization of white and black racializes whiteness, causing it to lose it normative functioning since whiteness exist as a "pure" category. But because whitenes is equalized, whiteness vanishes, and the mixed individual lapses into an existence polarized towards blackness. This "mixed" individual is understood as non-white and remains in the racial binary. Gordon suggests a more radical approach of overthrowing the normativity of whiteness. He suggests that humanity must whiteness. He suggests the hu experience a blackened world in order to overcome racism. This notion of a "blackened" world hints towards moral responsibility in
an oppressive world. Through the rejection an oppressive world. Through the rejection of whiteness and an abstract moral grounding in blackness, one can actively stand to destroy the foundation that advantages whiteness by causing a pressing need to respond to the sociopolitical implications of nonwhiteness. Fo Gordon, an emancipatory instance arises when a society is created in which there will be a more pressing need to attend to this racism.

Strengths and Weaknesses of Zack and Gordon's Claims

From here, I will compare and critique both theorists' claims. In comparison to Gordon, Zack's more simplistic version of the racial binary system neglects to include the way race functions in terms of the visual coloring of a person. Her focus appears to be on legalistic classificatory conventions rather than what varying degrees of skin color mean to a society infused with the principles that Gordon highlights as setting the conditions for antiblack racism. If we are concerned with a critical mixed race theory that works to solve the problem of racism, there must ing of the hierarchical and the implications a mixed race designation would include.
Since Zack's binary oversimplifies, her theory of mixed race is similarly one-dimensional. She posits that mixed race will function as "racelessness" and thus, antirace, but what Zack fails to acknowledge is the way racelessnes currently functions in society. As Gordon's pin wite sturds on top of the value schene of a society, whites top or the value scheme of a If whiters exists as that which eveything exists as that which everything is compared against, race then functions below

Zack states, "An American who identifies herself as mixed black and white race is a new person racially because old racial categories do not allow her to identify herseff this way."7 But "s "newness racially" provides the choice of racelessness does not account for the way racelessness already functions in society, bringing Zack's binary logic back into question.

In reference to an earlier quote by Gordon .... critical discussion of mixed-race categories calls for an understanding of how binary logic functions in discourses on race and racism. Without binaries, no racism will exist." 8 If he primary obligation to eliminating racism eliminating the binary, a useful mixed race understanding must account for this. A mixedrace identity does not work outside Zack's oversimplified binary - for the very essence of calling oneself "mixed" depends upon the black and white identities created by the binary system. Even if it seeks to act as a transgression of the binary, it relocates racial categories rather than separating from them. Calling rather "mixd" sts the developel practical and radical way to address the issue of 
racism from a mixed race standpoint.

Gordon's critique offers a deeper analysis of mixed race and racism. He acknowledges that simply identifying as mixed race does not sufficiently address racism since it does no directly attack the root causes of racism. The problem is the racial binary and its dependence on power hierarchies.

on power hierarchies.
Gordon's advocacy of a "blackening" or Gordon's advocacy of a "blackening" or
"coloring" of the world is shown as a way to promote the urgency of response to racism. This would force a shift in focus away from binary logic, its racist foundation, and white normative logic. I contend that focusing on the visual aspects of persons of mixed race will offer similar need to shift the binary's focus. "Mixing" the world (having more visually mixed persons) would require deconstruction of the binary by would require deconstruction of the binary by
disrupting the established relational hierarchy of visual whiteness and blackness.

Both theorists' concentration on the selfidentification of race asks whether reliance on the individual to claim mixed-race or engage in blackening the world may be too weak to solve a highly relational problem. Looking solely at the self-identification angle of mixe solely at the self-identification angle of mixed
race neglects the benefits to the social world of race neglects the benefits to the social world of
individuals appearing mixed race in terms of individuals appearing mixed race in terms of their epidermal or morphological schema. It is my contention that there is the visual element of mixed race that will bring about a critical mixedrace theory focused on eliminating racism.

\section{The Visually Mixed Race Individual}

Since racist laws are no longer explicitly coded, the struggle against racism is to alter coded, the struggle against racism is to alter attitudes and beliefs. Direct action may
be difficult and thus dialogue is crucial as a method to bring people's attitudes and perception to the for focus on the mixed race individual and healthy interracial relations offers a unique possibility to directly deal with issues of de facto, opposed to historically coded racism.

The very existence of a mixed individual can spark discussion. The visual transgression of the racial binary actively creates confusion. This confusion has the power to actively debunk notions of firm racial binary logic. Our immediate categorizations based on epidermal schema fall into either white or black. With the mixedrace individual, curiosity arises. As the "onedrop" rule fades from cultural understanding new ways of conceptualizing race entanding is important to recog hize the mixed inge. It is important to recognize the mixed individua as one who visibly transgresses the established binary racial distinction, but the solution is no to simply add a new category. The "mixed race" label does little to advance discussion. By merely adding another category, the foundation of logic which promotes racism, (1) to be white and (2) to not be black, is not destroyed but rather set aside in order to incorporate yet another distinction between individuals. This lini to radicts opportunity is socilly coddress the racian binary. If racism asserting herself as "mixed race" fundamentally confront racism in any way? Perhaps a turn should be had in looking at the societal levelwhat would a truly "raceless" or "colorblind" nation look like? Should colorblindness even be the ideal political future? One would have to be physicaly blind not to see varing in skin to be nd not to see variance in skin tone. Race should not be an "identity" in terms of its self-ascription, but a means of identification in person would not be white but simply have ligh skin. I would argue that with a social climate that encouraged interracial relations which in turn fostered an environment of mixed individuals, physical descriptions of race would not fall into a type of "colorblindness" (wherein one did not "see" color) but rather a space where one "ot "se" colo ishy see a spectrun could quite visibly see a spectrum of col skin tone to the point where categorizations of individuals based on this factor would have no purpose or logic.

It could be said, however, that group diversity is an important factor of society and the reduction of such group categorizations to the individual level--such that they no longer have purpose--neglects both the sociocultural as well as in some ways, the biological significance of social grouping. As Lucius Outlaw states,

Why argue for the conservation of races?-"I do so because I am thoroughly convinced that a rich diversity of social and cultural life-worldmaking, decent (breeding) populations are crucial to human species-being, Both the human biological genome and our various cultural genomes, if you will, are enriched by population-group diversity as well a biological and cultural individuaty, and the prospects for human survivability and adaptability enhanced accordingly.

While social groupings within a larger society are important and indeed necessary, I am not agreement that they need to or even should come through our ideas of race and racial identity. Also, with technology and our ability to move about the world quickly and connect with those who might be deemed "cultural others" social groupings and biolc geography are becoming less and less exclusive.
Outlaw would also state that the racial binary or simply having what we understand as two distinct races is not in and of itself conducive to racism. ${ }^{10}$ However, this vision is only the case from a neutral or removed perspective-one we can never fully grasp. It is an unfortunate we live in a society hat continues to interaction and political institution and as individus political institutions and we, The racial binay's foped by these interactions. The racial binary's foundation lies within these racist interactions. The binary and its logic go hand in hand here; we cannot neatly separate its functioning from the logic that upholds it. Therefore through analysis of the logic that The

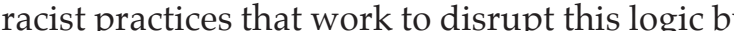
disrupting the binary itself.

\section{Interracial Relations and Individua} Racial Identity

As stated, perhaps what is needed to address the issue of racism is not more people identifying as mixed race, visually incoherent with established black/ white binaries. In order for this to occur, it would follow that interracial relations would have to be strengthened to provide for a social climate that encouraged and supported these relations, but this appears as a kind of "catch-22." It seems that healthy interracial relations and thus the creation of more individuals of visibly mixed race would not occur without first getting rid of rocis racism as a social construction coded by binary 
racial logic, perhaps a dynamic change in the know of their ability to essentialize an individual social context would simultaneously include or groups of individuals. In that respect, I find both internal and external changes in terms of it necessary to go beyond asserting oneself as interracial relations and mixed-race individuals. mixed race. To say that mixed race identity Approaching the issue from the individual level stands as the "antirace" neglects the socia and the societal level could blur the distinct between cause and effect in terms of how more functionally approaches the racial binary, to eradicate racism. Internal changes would positing it as more of a sliding scale hierarchy address attitudes about interactions between where the break occurs between whiteness and races while external changes to our environment all else (non-whiteness). Therefore, when one would involve visual opposition to the black/ self defines amidst a social world, a sense of white dichotomy and individuals who did allegiance is declared and certain social and not label themselves with the firm distinction political implications develop. This conception of of "mixed race" but rather, as a great matter the racial binary incorporates mixed individuals" of their existence, stood as an opportunity for position, and thus, Gordon concludes, mixed a por discourses on and deconstruction of binary race identity cannot form a critical theory nalysis to occur.

Use of both formal programs as well as selfmotivated actions can be used to facilitate more contact and interaction between differently raced peoples. Practical engagement in issues of race are crucial in addressing the way racism currently functions in our nation. Using this theoretical approach to mixed race posits the visually mixed race individual as a locus of social change. Conceivably, anyone can actively place himself in the position to be a locus of positive social change, but what is specifically awarded to the visibly mixed race individual is the passive means of inciting confusion and questioning amongst others in the social world, regardless of the mixed individual's active stance.

With a concentration on the visual appeal Zack and Gordon's analyses can be combined to further theorize mixed race and racism. I concede further the cizen's aixed race and becom. I concede that mixed race identity is going to occur because of one's need to sef-define. Itis not my belief that one should actively avoid publicly announcing mixed racial makeup, but such designations must the current hierarchical binary logic of race. However, Gordon does not seem to consider the benefits more persons of visual mixed race would have in deconstructing the racial binary today, which relies heavily on the visual aspects of race. Perhaps incorporating Zack's vision of an emancipatory mixed race theory and Gordon's careful and reflective thought on the subject, a mixed race theory focused on the visual appea of the mixed race individual, (rather than the public self-identification aspect) compounded of more mixed race individuals, will form a line of thought focused on abolishing racism.

\section{Conclusion}

Visual transgression of the racial binary can ork in a powerful way, both on the individual level as well as the societal. The mixed individual has the power to incite confusion on eradicating racism, as it does not disrup with encouraging a healthy space for the creation especially if a term such as "mixed race" is used to open channels of discourse rather than stand as a closed topic of classificatory convenience. In that sense, it is important that a term such as "mixed race" not become solidified in discourses on race. This creates space for new ways of conceptualizing race and discredits the racial binary. But what about the claim that mixed race is already included in this binary logic? With the slow death of the "one-drop rule," the binary has shifted and become fairly more fluid, thoug a firm distinction between white and non-white remains. The power mixed race has on affecting this type of binary comes on a more massive scale. Similar to Gordon's idea of "blackening", increased numbers of visually mixed people creates a pressing need to attend to racism in its anticolored forms while questioning the binary visibly overcoming the logic that supports it. The very "newness" of a mixed race identity The very "new nes" of a mixed race identy critique on race itself and the structures that rece untol binary racial logic. Thefore, through (t) engagement with the topic of mixed race, there exists a key outlet for addressing the problem of racism that cannot be ignored. 